\title{
EDUCAÇÃO INCLUSIVA: A NECESSIDADE DE MUDANÇAS DE PARADIGMAS E REVISÃO DE CONCEITOS
}

\author{
ARTIGO ORIGINAL \\ MEDEIROS, José Marcos de ${ }^{1}$ \\ MEDEIROS, Sandra Barbosa Silva de ${ }^{2}$ \\ MEDEIROS, Sanmily Silva de ${ }^{3}$ \\ SILVA, Carmelo Sousa da ${ }^{4}$
}

MEDEIROS, José Marcos de. Et al. Educação Inclusiva: A necessidade de mudanças de paradigmas e revisão de conceitos. Revista Científica Multidisciplinar Núcleo do Conhecimento. Ano 05, Ed. 03, Vol. 02, pp. 05-16. Março de 2020. ISSN: 2448-0959, Link de acesso: https://www.nucleodoconhecimento.com.br/educacao/mudancas-deparadigmas

\section{RESUMO}

O presente trabalho aborda discussões sobre a nova perspectiva da Educação Inclusiva bem como discute sobre a necessidade de mudança de paradigmas e da revisão de conceitos. Não temos como objetivo apresentar uma receita pronta para elucidar os problemas ou criar paradigmas, mas sim fomentar a discussão por entendermos ser relevante na época em que vivemos. Já que esta temática tem sido

1 Pós-Graduado em Pedagogia: Gestão e Planejamento Escola pela FACOL Faculdade Escritor Osman da Costa Lins.

2 Pós-Graduada em Pedagogia: Gestão e Planejamento Escola pela FACOL Faculdade Escritor Osman da Costa Lins.

${ }^{3}$ Graduanda em Enfermagem pela Universidade Federal de Pernambuco.

${ }^{4}$ Mestre em Educação pela Universidade La Empresa - UDE, Montevidéu - UY. 
discutida há vários anos, analisar-se-ão alguns subsídios importantes que são a base legal de uma Educação Inclusiva (El) como a Constituição Federal de 1988, a Lei de Diretrizes e Base da Educação, a Conferência de Educação Para Todos (promovida pela ONU) e, também, o Estatuto da Criança e do Adolescente. Dada a relevância que a El representa, buscamos esclarecer alguns pressupostos no que diz respeito ao direito, diversidade, currículo e adaptações a fim de identificar fatores que contribuem para com a diferenciação pedagógica, visando alcançar uma perspectiva de escola inclusiva que respeita as diferenças individuais.

Palavras-chave: Educação inclusiva, paradigma, currículo, adaptações.

\section{INTRODUÇÃO}

O presente trabalho aborda discussões sobre a nova perspectiva da diversidade no contexto da educação inclusiva cujo ingresso da inclusão social educacional possibilita o convívio de pessoa com deficiência com as outras tidas como "normais, podendo, assim, adquirir novos conhecimentos sobre realidades diferentes. A educação inclusiva, dentro da perspectiva de uma educação para todos, constitui um grande desafio na realidade nacional e aponta uma numerosa parcela de excluídos do sistema educacional sem a menor possibilidade de acesso à escolarização. Daí a relevância de um estudo mais detalhado desta temática. Não temos como objetivo apresentar uma receita para elucidar problemas ou criar paradigmas, mas sim fomentar a discussão por entendermos ser relevante e contemporânea na sociedade que vivemos.

Falar desta temática é manifestar angústias e insatisfações de toda ordem, de maior ou menor relevância, dependendo do grau de constrangimento imposto por barreiras instituídas de diferentes práticas sociais. A Constituição Federal (1988) e a Lei de Diretrizes e Bases da Educação Nacional (Lei o 9.394/96) estabelecem que a educação é direito de todos, garantindo, então, a partir dos seus dispositivos, o atendimento educacional especializado às pessoas com deficiência. As duas últimas décadas foram marcadas por movimentos sociais muitos importantes, organizados 
por defensores dos direitos humanos e pessoas com deficiência que conquistaram o reconhecimento do direito e participação social das pessoas com deficiência.

A partir desta conquista os instrumentos internacionais que passaram a orientar reformulações dos marcos legais de todos os países, inclusive do Brasil, ganharam fama. Uma vez que cerca de $10 \%$ da população brasileira apresenta algum tipo de deficiência se torna imprescindível que as escolas estejam preparadas para lidar com a diversidade. Isso significa introduzir uma nova ética: a ética da diversidade, visto que rompe com a ideia de um modelo padrão de humanidade e de adaptação dos excluídos. Portanto, o que se defende é a construção de uma sociedade inclusiva e que estabelece um compromisso com as minorias, dentre as quais se inserem as pessoas com deficiência. A educação inclusiva propõe que todas as pessoas que tenham qualquer tipo de deficiência sejam matriculadas na escola regular, baseandose no princípio de uma educação para todos.

Mas é preciso ser cauteloso no sentido de não admitir uma ideia falsa de escola democrática. A escola será mais democrática à medida que acolher, ensinar e educar a todos ao mesmo tempo em que respeita as diferenças individuais, estimulando, assim, o desenvolvimento da capacidade do educando de aprender a aprender. De acordo com este novo paradigma educativo, a escola deve ser aberta à pluralidade $e$ atender a todas as crianças, sem exceção, e, também, deve contar com uma educação de qualidade. Como diz Mantoan (1997), cabe, à escola, encontrar respostas educativas para as necessidades de seus educandos e exigir dela uma transformação.

Considerando este contexto, é válido reiterar que não basta fazer adaptações físicas, mas é preciso, também, e, principalmente, transformar a sua prática pedagógica, isto é, é essencial inserir em suas classes regulares a pessoa com deficiência que está em busca de seu desenvolvimento pleno e exercício da cidadania, fazendo com que todas as pessoas com deficiência, ou não, tenham oportunidades iguais em termos de vivência à riqueza que a diferença representa, e, com isso, é fundamental fortalecer a solidariedade ao próximo. Sob esta circunstância, é fundamental a consciência 
crítica do profissional de educação e de sua responsabilidade pela aprendizagem dos seus educandos, o que inclui o deficiente.

\section{INCLUSÃO EDUCACIONAL, DIREITO DE TODOS}

Vivemos em uma sociedade democrática que tem como objetivo defender a pluralidade, a interlocução e o convívio na diversidade. O direito de participar nos espaços e nos processos comuns de ensino realizados pelas escolas está previsto na legislação e nas políticas educacionais. A Constituição Federal de 1988 igualmente consagra, no Art. 205: "a educação como direito de todos e dever do Estado e da família, da sociedade, visando ao pleno desenvolvimento da pessoa, seu preparo para o exercício da cidadania e sua qualificação para o trabalho". No Art. 206, temos a oportunidade de destacar princípios eminentemente democráticos, cujo sentido é encaminhar a educação, tais como:

I - Igualdade de condições para o acesso e permanência na escola; II Liberdade de Aprender, ensinar, pesquisar e divulgar o pensamento, a arte e o saber; III - Pluralismo de ideias e de concepções pedagógicas e coexistente de instituições públicas e privadas de ensino; [...] (CONSTITUIÇÃO FEDERAL 1988, Art. 206,I,II).

Nesse contexto, a Constituição assegura que todos podem ter os mesmos direitos, sem nenhuma restrição à permanência no âmbito escola, pois seu objetivo é de promover o bem de todos, sem preconceito de origem, raça, cor, sexo, idade ou quaisquer outras formas de descriminação. Ela prevê uma sociedade com escolas abertas a todas as pessoas com deficiências, pois educação não é de apenas uma parcela da sociedade. Constitucionalmente, prevemos que as crianças e adolescentes com deficiências têm esses direitos garantidos, uma vez que todos os textos legais analisados até agora afirmam o princípio da não-discriminação.

Mas há ainda outros dispositivos legais que reafirmam os direitos dessas pessoas, como a Lei de diretrizes e Bases da Educação (Lei n.. 9.394/96) que apresenta características básicas de flexibilidade além de algumas inovações que favorecem as 
pessoas com deficiência. É pela primeira vez que aparece em uma LDB um capítulo (Cap. V) destinado à Educação Especial, para efeito desta Lei, a modalidade de educação escolar, oferecida principalmente na rede regular de ensino, para educandos com deficiência, no parágrafo $3^{\circ}$ é entendida como: "a oferta de educação especial, dever constitucional do Estado, tem início na faixa de zero a seis anos, durante a educação infantil”. Em seu Art. 59, III, ela afirma que não basta apenas incluir os educandos, mas é preciso que haja professores qualificados para lidar com este público.

Considerando este contexto, deve-se salientar que é também muito importante que haja o compromisso real e eficiente do poder público de ampliar o atendimento aos educandos com deficiência na rede pública de ensino, o que implica na criação de políticas públicas voltadas a este acesso. É oportuno reconhecer que a escola terá que adaptar-se à diversidade. Como instituição social, ela não pode continuar segregando, pelo contrário, é preciso que estejam preparadas para lidar com as diferenças e demandas presentes por meio da valorização, do planejamento e da implementação de propostas pedagógicas comprometidas com a diversidade e a flexibilidade curricular. De acordo com os Parâmetros Curriculares Nacionais:

Deve-se dar especial atenção ao aluno que demonstra a necessidade de resgatar a autoestima. Trata-se de garantir condições de aprendizagem a todos os alunos, seja por meio de incrementos na intervenção pedagógica ou de medidas extras que atendam às necessidades individuais (PCN, 1997, p. 26).

Ao trabalhar com a diversidade, os educadores serão desafiados a serem ousados e criarem mecanismos que favoreçam a remoção de barreiras que impedem o desenvolvimento e o potencial dos educandos. Nesta perspectiva, Gomes (2008) afirma que não será suficiente incluir as crianças com deficiência na escola regular se também não realizamos um processo de reeducação do olhar e das práticas. Na visão da autora, não basta acolher ou garantir a permanência das crianças na escola, o mais importante no processo inclusivo é promover o bem-estar de todos e a aprendizagem coletiva. A importância de fazer da inclusão um direito de todos e um 
movimento coletivo de mudança aponta para a adoção de políticas educacionais inclusivas, para a transformação das práticas sociais, para a transformação dos institutos escolares e para a criação de relações com a família e com a comunidade.

Assim sendo, é válido destacar que essas políticas devem prever, principalmente, a eliminação de todos os tipos de barreiras relacionadas e associadas à educação dos educandos portadores de quaisquer deficiências, promovendo, dessa forma, a participação desses a partir de novas relações entre os educandos, uma vez que são fundamentais para que haja uma socialização humanizadora, visando, sobretudo, a valorização da diversidade em todas as atividades, espaços e formas de convivências no contexto escolar. A inclusão social educacional tem provocado inúmeros debates a respeito dos direitos educacionais. Portanto, estar na escola é um direito que deve ser assegurado pelo estado. Nesta mesma perspectiva, a Organização das Ações Unidas, em seu Art. $2^{\circ}$, estabelece que:

1. Os Estados-partes respeitarão os direitos previstos nesta Convenção e os assegurarão a toda criança sujeita à sua jurisdição, sem discriminação de qualquer tipo, independentemente de raça, cor, sexo, língua, religião, opinião política ou outra, origem nacional, étnica ou social, posição econômica, impedimentos físicos, nascimento ou qualquer outra condição da criança, de seus pais ou de seus representantes legais.

2. Os Estados-partes tomarão todas as medidas apropriadas para assegurar que a criança seja protegida contra todas as formas de discriminação ou punição baseadas na condição, nas atividades, opiniões ou crenças, de seus pais, representantes legais ou familiares. (UNESCO, 1994, Art. 2ํㅜ, 1 e 2).

O Estatuto da Criança e do Adolescente (ECA), Lei 8.069 de 13 de julho de 1990, consolida a convenção e determina que: 
Nenhuma criança ou adolescente será objeto de qualquer forma de negligência, descriminação, exploração, violência, crueldade e opressão, punindo na forma da lei qualquer atentado por ação ou omissão aos seus direitos fundamentais (ECA, 2009, Art. 5ํ).

Deve-se destacar, também, que o Art. 18, afirma que: "é dever de todos velar pela dignidade da criança e do adolescente, colocando-os a salvo de qualquer tratamento, desumano, violento, aterrorizante, vexatória ou constrangedor". Assim sendo, é preciso compreender que a inclusão social se refere às ações que combatem a exclusão social que se manifesta a partir das relações pessoais, devido, sobretudo, às questões oriundas de fatores, como, por exemplo, a classe social, o nível educacional ou em razão da deficiência de diversas naturezas. Nesse sentido, tornase relevante destacar, considerando a literatura, que:

Nosso país não pode desperdiçar ninguém e precisamos investir no enorme potencial de cada pessoa através da implantação da Lei dos Americanos com Deficiências. A minha Administração compromete-se a mudar a política pertinente à deficiência: da exclusão para a inclusão para a inclusão, da dependência para a independência do paternalismo para o empowerment" - Discurso proferido pelo Presidente dos E.U.A, Bill Clinton, em 23/07/93 (SASSAKI,1997 p. 11).

Nessa perspectiva, é de suma importância compreender que a discriminação, a partir dos atos discriminatórios e preconceituosos que se manifestam nas relações sociais, fazem com que essas pessoas que portam algum tipo de deficiência, fiquem, de alguma forma, isoladas da sociedade, e, com isso, sem ter acesso à cidadania plena que é merecida por direito. Portanto, é necessário que haja um investimento nessas pessoas para que possam desenvolver suas habilidades e competências. $O$ presidente dos Estados Unidos da América, Bill Clinton, chama a nossa atenção a respeito da importância da valorização da inclusão para amenizar tal problemática. 


\section{PARADIGMA DA DIVERSIDADE}

Na maioria das vezes, as diferenças entre educando são vistas como um problema. Muitas pessoas acreditam que as diferenças dos educandos em relação às adaptações são dificuldades que necessitam ser trabalhadas e mudadas, ou, ainda, que os educandos precisam estar preparados para se adaptarem à situação de aprendizagem e estas situações podem se tornar inconvenientes, prejudicando, assim, o desenvolvimento da aprendizagem dos educandos. Segundo Fletcher (1996):

Tradicionalmente, a deficiência tem sido vista como um problema do indivíduo e, por isso, o próprio indivíduo teria que se adaptar à sociedade ou ele teria que ser mudado por profissionais através da reabilitação ou cura (FLETCHER, 1996, p. 7).

Estas expectativas e limitações predefinidas dos valores dos educandos estão sendo ampliadas e mudadas para uma inclusão que ocorrerá como uma posição educacional satisfatória nas escolas e nas salas de aulas. No Art. 22 da Declaração de Viena (1994) expressa-se que:

Deve-se dar atenção especial às pessoas portadoras de deficiências visando a assegurar-Ihes um tratamento não-discriminatório e equitativo no campo dos direitos humanos e liberdades fundamentais, garantindo sua plena participação em todos os aspectos da sociedade (DECLARAÇÃO DE VIENA, 1994, p. 183).

Para que a construção da prática da inclusão seja bem sucedida, as diferenças dos educandos devem ser reconhecidas como um recurso positivo que favorecerá a aprendizagem de todas as pessoas com deficiências. As diferenças entre eles devem ser reconhecidas e reunidas para fornecer oportunidades de aprendizagem para todos os educandos da escola. De acordo com Fávero (2004): 
A inclusão é um desafio, que ao ser devidamente enfrentado pela escola comum, provoca a melhoria da qualidade da Educação Básica e Superior, pois, para que os alunos com e sem deficiência possam exercer o direito à educação em sua plenitude, é indispensável que essa escola aprimore suas práticas, a fim de atender às diferenças. Esse aprimoramento é necessário, sob pena de os alunos passarem pela experiência educacional sem tirar dela o proveito desejável, tendo comprometido um tempo que é valioso e irreversível em suas vidas: o momento do desenvolvimento (FÁVERO, 2004, p. 30).

É importante equipararmos as oportunidades para que todas as pessoas com deficiências possam ter acesso aos serviços sociais e à realização de seus sonhos na sociedade. Segundo Sassaki, citado por Mantoan (1997), a inclusão questiona não apenas as políticas ou a organização da educação especial e regular, visto que contempla, ainda, o mainstreaming. Nesse sentido, a principal missão da inclusão é não deixar ninguém de fora desse ensino regular que é um direito de todos, independentemente de sua deficiência, desde os primeiros níveis da educação até o último. Amparar todos aqueles que, de alguma forma, estão ou já foram excluídos é um dos principais objetivos da educação inclusiva.

\section{CURRÍCULO, ADAPTAÇÕES E DIFICULDADES}

A inclusão educacional é anunciada como a forma mais recomendável para o atendimento dos educandos com deficiências, altas habilidades e condutas típicas de síndromes. Esta integração é identificada hoje como o caminho mais eficiente para a construção da cidadania e participação social em conformidade com a perspectiva da educação para todos e com todos. Sobre este prisma, a Organização das Nações Unidas para a Educação, Ciência e Cultura estabelece que:

[...] todas as crianças deveriam aprender juntas, independente de quaisquer dificuldades ou diferenças que possam ter. As escolas inclusivas devem reconhecer e responder às diversas necessidades de seus alunos, acomodando tanto estilos como ritmos diferentes de 
aprendizagem e assegurando uma educação de qualidade a todos, por meio de currículo apropriado, modificações organizacionais, estratégias de ensino, usam de recursos e parceria com a comunidade (UNESCO, 1994, p. 5).

Inserir educandos com deficiências na rede regular de ensino é o primeiro passo para a inclusão, mas não pode ficar por aí. O próximo passo deve ser seguido de medidas pedagógicas que garantem o acesso à aprendizagem e ao conhecimento proposto na vivência escolar. Interpretando na prática, é preciso acionar os meios que possibilitam a permanência do educando na escola, favorecendo o acesso ao currículo. Sabemos que o currículo é um conjunto de experiências que a escola, como instituição, põe à serviço dos educandos com a finalidade de desenvolver seus potenciais, suas competências e habilidades integrais. Não defendemos a ideia de um currículo fixo ou fechado, mas sim um instrumento participativo, resultante das vivências e expectativas socioculturais que revelam a importância da diversidade na escola. Cabe, ao instrumento, responder essas demandas.

A inclusão na realidade brasileira apresenta algumas dificuldades: resistência da comunidade escolar na aceitação dos educandos, despreparo do sistema regular de ensino para atuar no processo e outros fatores diversos de natureza familiar, sociocultural e institucional. Várias dificuldades ocorrem quando a escola regular não permite $\mathrm{o}$ acesso dos educandos com deficiências às situações educacionais comuns e afetam, também, os demais educandos. As deficiências que alguns educandos apresentam devem ser atendidas pelo currículo regular por meio de ajustes. Se entendermos o currículo como um conjunto de ações que a escola oficializa em consonância com o Projeto Político Pedagógico, o processo educativo assim orientado é o mesmo para todos os educandos com a devida atenção às diferenças, inclusive, as diferenças mais acentuadas que se observam em alguns educandos são parecidas com as dos demais.

Os Parâmetros Curriculares Nacionais (1997) constituem referências válidas para orientar a educação dos educandos de um modo geral e daqueles com deficiências, os quais pressupõem objetivos e indicações e consideram questões pedagógicas 
atuais, admitindo a pluralidade de concepções pedagógicas e do fazer educativo, a diversidade dos alunos na escola e as particularidades de sua cultura. A escola tem demonstrado que a inclusão pode ser favorecida quando se observam as seguintes providências: apoio especializado para os que necessitam; preparação e dedicação dos professores; a realização de adaptações curriculares e o acesso ao currículo. Estas medidas de adequação curricular requerem análise à parte.

De um modo geral, o currículo pode constituir um grande obstáculo para os educandos com deficiências educacionais na escola regular, especialmente quando ele força uma referência homogênea a ser alcançada por todos os educandos, independentemente de suas necessidades particulares que podem apresentar. O que buscamos é um currículo aberto, transformador e com novas prescrições, de modo a contemplar a todos os educandos com deficiências. Segundo Guijarro (1992), os procedimentos de adaptações curriculares foram defendidos como um conjunto de modificações que se realizam nos objetivos, conteúdos, critérios e procedimentos de avaliação, atividades e metodologias para atender às diferenças individuais dos alunos.

O autor distingue as adaptações de acesso ao currículo as definindo como as modificações ou provisão de recursos especiais, materiais ou de comunicação que favorecem o aluno com deficiência no desenvolvimento do currículo adaptado. Portanto, os procedimentos adaptativos citados aplicam-se aos seguintes elementos curriculares: objetivo, conteúdos, avaliação, temporalidade, organização curricular, metodologia e organização didática. Estas adaptações realizam-se de acordo com as necessidades do educando, podendo ser dispensadas ou aplicadas de forma reduzida ou, ainda, de forma mais intensiva, dependendo da necessidade dos educandos. Esta adaptação ganha respaldo na Lei n. 9.394/96 de Diretrizes e Bases da Educação Nacional, em seu Art. 59). A educação inclusiva não se acaba na observância da lei, que a reconhece e garante, mas solicita uma mudança de postura e de opinião dos sistemas educacionais. As modificações necessárias devem abranger atitudes, organização, perspectivas e ações de operacionalização de trabalho educacional. 


\section{CONSIDERAÇÕES FINAIS}

A partir das informações obtidas durante a pesquisa fomos nos convencendo de que realmente há uma diferença muito grande entre o que as leis afirmam ser de direito das pessoas com deficiências e o que é realmente oferecido pelas instituições escolares. Por um lado, surgem as leis com inúmeras garantias, e, por outro, há as práticas equivocadas. Portanto, a educação inclusiva suscita imediatamente um redimensionamento nas políticas públicas. A inclusão é algo muito complexo e exige que toda a sociedade se reorganize para lidar com este grande desafio. As pessoas com deficiências desejam apenas uma educação de qualidade, sob a qual possam desenvolver suas habilidades e competências como cidadãos.

Uma vez que este direito é garantido por lei, isso determina que as instituições estejam sensibilizadas, comprometidas, e, principalmente, preparadas para deflagrar ações específicas para o atendimento deste público. Para que a inclusão possa assumir seu verdadeiro papel é preciso que haja uma mudança no sistema educacional e que haja, também, a realização de uma avaliação permanente nas instituições para que sejam corrigidas as barreiras que ela enfrenta. É preciso haver, ainda, coerência entre o que as leis garantem e o que é efetivamente posto em prática. Nesta fase, é importante não só a qualificação dos professores, mas também de toda a equipe envolvida no processo educativo.

Esperamos, com este estudo, ter contribuído para minimizar as dúvidas enfrentadas atualmente acerca da educação inclusiva, sejam elas no que diz respeito às leis ou à questão curricular e de adaptações. Observamos, ainda hoje, atitudes de descriminação que repudiam o ser humano e que são reflexos de uma sociedade capitalista e discriminatória. É preciso que toda a sociedade se mobilize em defesa da pessoa com deficiência e que haja uma valorização das suas potencialidades, oferecendo-lhes meios para desenvolvê-las ao máximo. Não termina por aqui este estudo. É necessário que outras pessoas continuem a pesquisa e realizem novas descobertas, pois esta temática é de fundamental relevância para a sociedade em que vivemos. 


\section{REFERÊNCIAS}

BRASIL. Constituição (1988). Constituição: República Federativa do Brasil. Brasília Senado Federal, Centro Gráfico.

BRASIL. Ministério da Educação. Lei de Diretriz e Bases da Educação Nacional. LDB no 9.394 de 20 de dezembro de 1996.

BRASIL. Ministério da Justiça/CORDE. Declaração de Salamanca e Linhas de ações Sobre Necessidades Educativas Especiais. Brasil: MJ/CORDE,1994.

BRASIL. Parâmetros Curriculares Nacionais: Introdução aos parâmetros curriculares nacionais. Ministério da Educação. Secretaria da Educação Fundamental. 3ª ed. - Brasília: Secretaria da Educação, 2001,97p.

CEDC-PE, Conselho Estadual de defesa dos Direitos da Criança e do Adolescente. Estatuto da Criança e do Adolescente. Lei o 8.069 de 13/07/90. Recife, Pernambuco, 2009.

FÁVERO, E. A. G. Direito das pessoas com deficiência: Garantia de igualdade na diversidade. Rio de Janeiro: Editora WVA, 2004.

FLETCHER, A. Ideias práticas em apoio ao Dia Internacional das pessoas com Deficiências: 3 de dezembro. Tradução por: Romeu Kazumi Sassaki. São Paulo: Prodef/Apade, 1996.

GOMES, N. L. Indagação sobre currículo: diversidade e currículo. Organização do documento Jeanete Beauchamp, Sandra Denise Pagl, Aricélia Ribeiro do Nascimento.- Brasília: Ministério da Educação, Secretaria de Educação Básica, 2008, $34 p$.

GUIJARRO, R. B. (org.). Alumnos com necesidades educativas especiales y adaptaciones curriculares. Espanha: Ministerio de Educación y Ciencia, 1992. 
MANTOAN, M. T. E. Ser ou estar, eis a questão: explicando o déficit intelectual. Rio de Janeiro: Editora WVA,1997.

SASSAKI, R. K. Inclusão: construindo uma sociedade para todos. Rio de Janeiro: Editora WVA, 1997.

UNESCO - Organização das Nações Unidas para a Educação, Ciência e Cultura / Ministério da Educação e Ciência da Espanha / Coordenadoria Nacional para Integração da Pessoa Portadora de Deficiência - Corde. Declaração de Salamanca e linha de ações sobre necessidades educativas especiais. Brasil, 1994. Dotada pela Resolução L.44 (XLIV) da Assembléia Geral das Nações Unidas, em 20.11.1989 - ratificada pelo Brasil em 24.09.

Enviado: Janeiro, 2020.

Aprovado: Março, 2020. 